\title{
Volcanism and the Little Ice Age
}

\author{
Thomas J. Crowley ${ }^{1 *}$, G. Zielinski ${ }^{2}$, B. Vinther ${ }^{3}$, R. Udisti ${ }^{4}$, K. Kreutz ${ }^{5}$, J. Cole-Dai ${ }^{6}$ and E. Castellano ${ }^{4}$ \\ 'School of Geosciences, University of Edinburgh, UK; Thomas.Crowley@ed.ac.uk \\ ${ }^{2}$ Center for Marine and Wetland Studies, Coastal Carolina University, Conway, USA \\ ${ }^{3}$ Niels Bohr Institute, University of Copenhagen, Denmark \\ ${ }^{4}$ Department of Chemistry, University of Florence, Italy \\ ${ }^{5}$ Department of Earth Sciences, University of Maine, Orono, USA \\ ${ }^{6}$ Department of Chemistry and Biochemistry, South Dakota State University, Brookings, USA \\ *Collaborating authors listed in reverse alphabetical order.
}

The Little Ice Age (LIA; ca. 1250-1850) has long been considered the coldest interval of the Holocene. Because of its proximity to the present, there are many types of valuable resources for reconstructing temperatures from this time interval. Although reconstructions differ in the amplitude of cooling during the LIA, they almost all agree that maximum cooling occurred in the mid- $15^{\text {th }}, 17^{\text {th }}$ and early $19^{\text {th }}$ centuries.

The LIA period also provides climate scientists with an opportunity to test their models against a time interval that experienced both significant volcanism and (perhaps) solar insolation variations. Such studies provide information on the ability of models to simulate climates and also provide a valuable backdrop to the subsequent $20^{\text {th }}$ century warming that was driven primarily from anthropogenic greenhouse gas increases.

Although solar variability has often been considered the primary agent for LIA cooling, the most comprehensive test of this explanation (Hegerl et al., 2003) points instead to volcanism being substantially more important, explaining as much as $40 \%$ of the decadal-scale variance during the LIA. Yet, one problem that has continually plagued climate researchers is that the paleo-volcanic record, reconstructed from Antarctic and Greenland ice cores, cannot be well calibrated against the instrumental record. This is because the primary instrumental volcano reconstruction used by the climate community is that of Sato et al. (1993), which is relatively poorly constrained by observations prior to 1960 (especially in the southern hemisphere).

Here, we report on a new study that has successfully calibrated the Antarctic sulfate record of volcanism from the 1991 eruptions of Pinatubo (Philippines) and Hudson (Chile) against satellite aerosol optical depth (AOD) data (AOD is a measure of stratospheric transparency to incoming solar radiation). A total of 22 cores yield an area-weighted sulfate accumulation rate of $10.5 \mathrm{~kg} / \mathrm{km}^{2}$, which translates into a conversion rate for AOD of $0.011 \mathrm{AOD} /$ $\mathrm{kg} / \mathrm{km}^{2}$ sulfate. We validated our time series by comparing a canonical growth and decay curve for eruptions for Krakatau (1883), the 1902 Caribbean eruptions (pri-

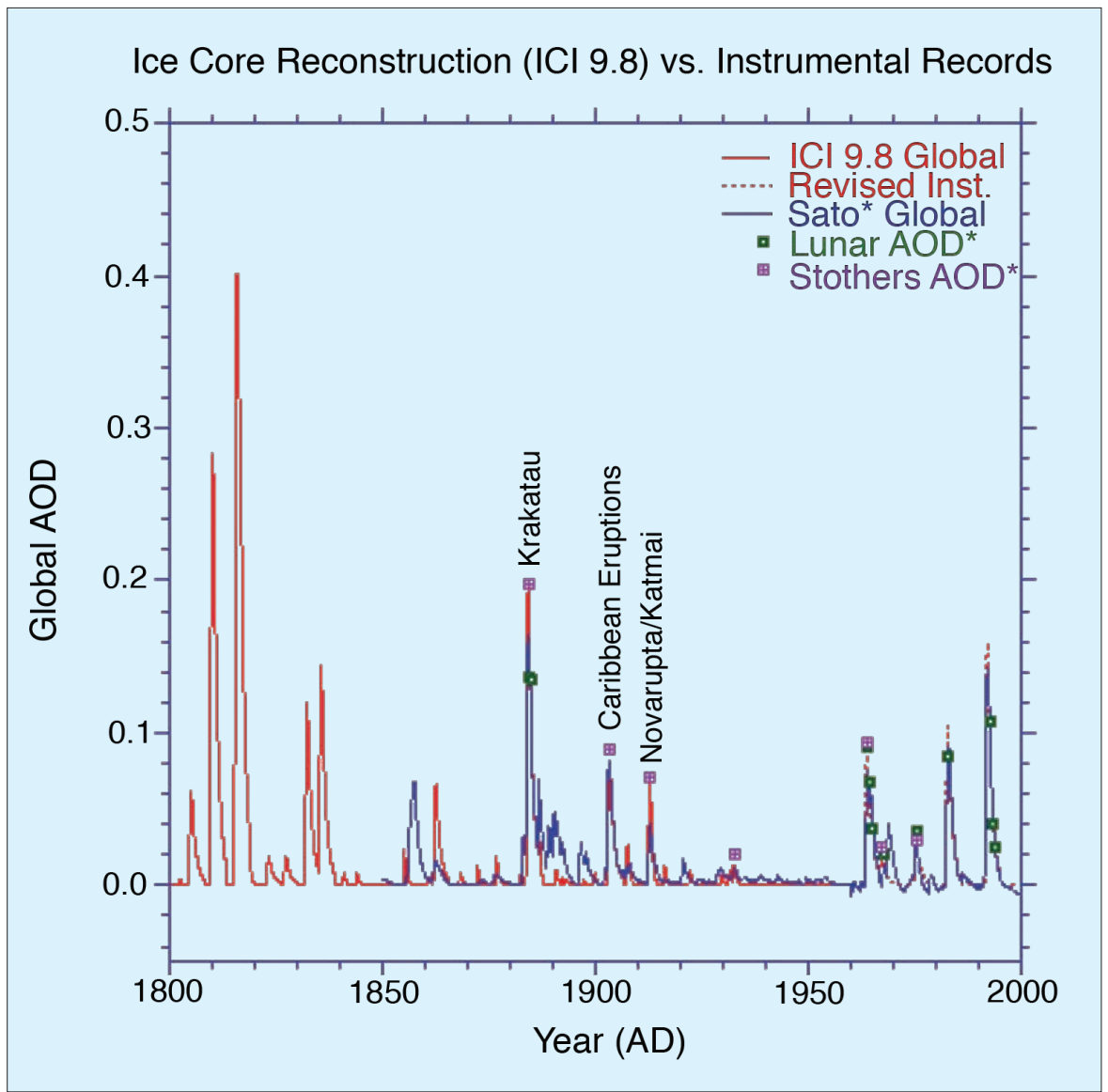

Figure 1: Comparison of new ice core reconstruction with various instrumental-based reconstructions of stratospheric aerosol forcing. The asterisks refer to some modification to the instrumental data; for Sato et al. (1993) and the Lunar AOD, the asterisk refers to the background AOD being removed for the last 40 years. For Stothers (1996), it refers to the fact that instrumental observations for Krakatau (1883) and the 1902 Caribbean eruptions were only for the northern hemisphere. To obtain a global AOD for these estimates we used Stothers (1996) data for the northern hemisphere and our data for the southern hemisphere. The recon,struction for Agung eruption (1963) employed Stothers (1996) results from $90^{\circ} \mathrm{N}-30^{\circ} \mathrm{S}$ and the Antarctic ice core data for 30-90 $\mathrm{S}$.

marily Santa Maria), and the 1912 eruption of Novarupta/Katmai (Alaska) against a reanalysis (Stothers, 1996) of the original AOD data and lunar eclipse estimates of AOD for Krakatau (Keen, 1983). The agreement (Fig. 1) is very good-essentially within the uncertainty of the independent data. Our new ice core reconstruction shows several significant disagreements with the Sato et al. (1993) reconstruction in the late $19^{\text {th }}$ and early $20^{\text {th }}$ centuries. As we have essentially the same number of records over the entire interval of the Sato et al. reconstruction, and their database decreases significantly prior to 1960 , we contend that our reconstruction for the earlier intervals is at least as good as that of Sato et al. It is, at the very least, a legitimate alternate reconstruction to use for this earlier time interval.
Although the above analysis may not permanently put to rest uncertainties about calibration of ice core sulfate data, it does represent an encouraging advance over present reconstructions. We therefore applied the methodology to part of the LIA record that had some of the largest temperature changes over the last millennium. A total of 13 Greenland and Antarctic ice cores were used as the main database, with spot data included from other cores. The ice core reconstruction was then compared (Fig. 2) against the temperature reconstruction of Jones et al. (1998), which indicates the standard cooling patterns discussed above, including the well known very severe cooling of the mid-1690s in western Europe.

The ice core chronology of volcanoes is completely independent of the (pri- 


\section{Volcanoes vs. Little Ice Age Temperatures}

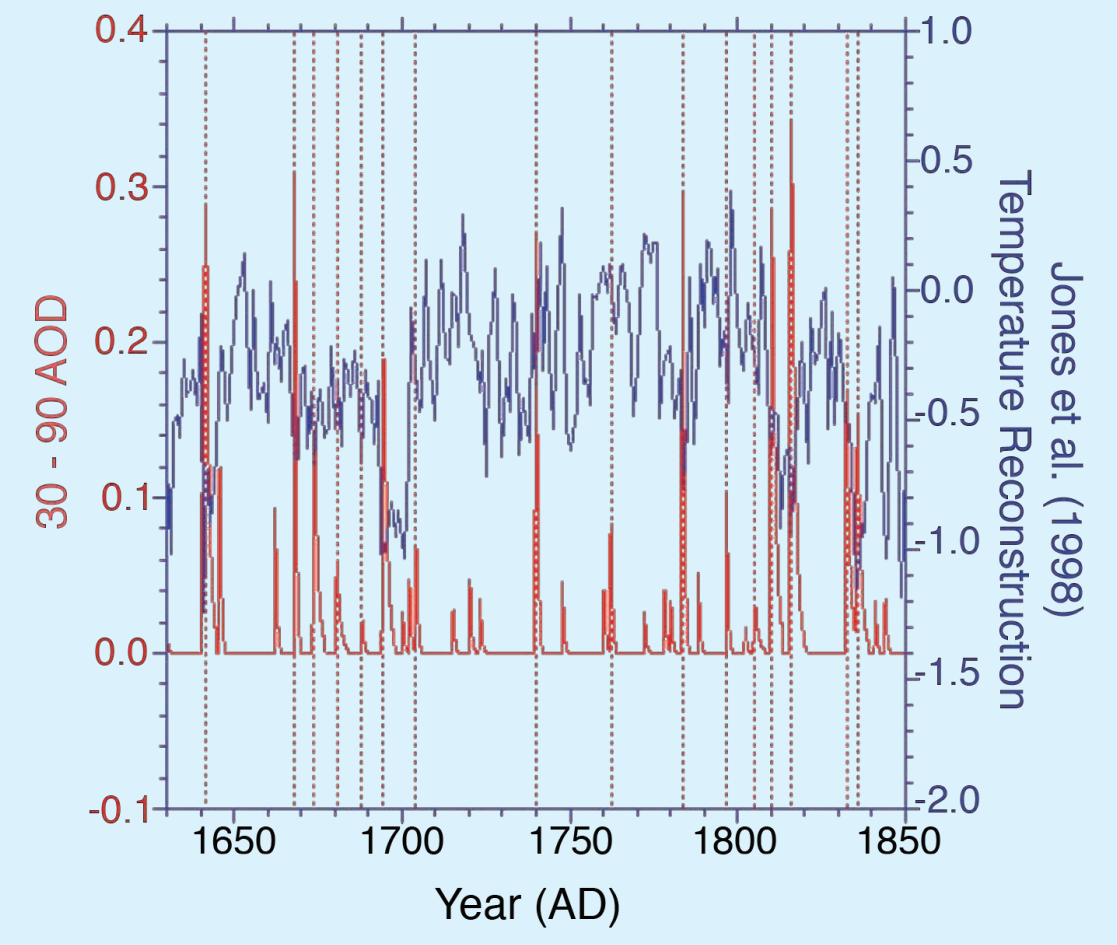

Figure 2: Comparison of $30-90^{\circ} \mathrm{N}$ version of ice core reconstruction with Jones et al. (1998) temperature reconstruction over the interval 1630-1850. Vertical dashed lines denote levels of coincidence between eruptions and reconstructed cooling. $A O D=$ Aerosol Optical Depth.

marily) tree ring based temperature reconstruction. The volcano reconstruction is deemed accurate to within $0 \pm 1$ years over this interval. There is a striking agreement between 16 eruptions and cooling events over the interval 1630-1850. Of particular note is the very large cooling in 1641-1642, due to the concatenation of sulfate plumes from two eruptions (one in Japan and one in the Philippines), and a string of eruptions starting in 1667 and culminating in a large tropical eruption in 1694 (tentatively attributed to Long Island, off New Guinea). This large tropical eruption (inferred from ice core sulfate peaks in both hemispheres) occurred almost exactly at the beginning of the coldest phase of the LIA in Europe and represents a strong argument against the implicit link of Late Maunder Minimum (1640-1710) cooling to solar irradiance changes.

During the $18^{\text {th }}$ century lull in eruptions, temperatures recovered somewhat but then cooled early in the $19^{\text {th }}$ century. The sequence begins with a newly postulated unknown tropical eruption in midlate 1804, which deposited sulfate in both Greenland and Antarctica. Then, there are four well-documented eruptions-an unknown tropical eruption in 1809, Tambora (1815) and a second doublet tentatively attributed in part to Babuyan (Philippines) in 1831 and Cosiguina (Nicaragua) in 1835 . These closely spaced eruptions are not only large but have a temporally extended effect on climate, due to the fact that they reoccur within the 10-year recovery timescale of the ocean mixed layer; i.e., the ocean has not recovered from the first eruption so the second eruption drives the temperatures to an even lower state.

The new reconstruction also predicts higher AOD levels for Krakatau than Sato et al. (1993). This has important implications for prior paleo-reconstructions, as the Sato et al. (1993) estimate has been a key calibration point for absolute scaling of the entire paleo-volcanic reconstruction. The new result implies that methods using the Sato et al. (1993) approach could underestimate the true magnitude of earlier eruptions by ca. $20 \%$. This conclusion represents just one of the many of the benefits of the new reconstruction.

A final benefit of the new reconstruction is that the uncertainty in the absolute magnitude of past volcanic forcing may be reduced by about one-half, to (tentatively) $10-15 \%$ (1 $\sigma)$. This reduction may have significant implications for estimating climate sensitivity from the record of the last 1000 years. For example, Hegerl et al. (2006) estimate that the range of climate sensitivity for the LIA was approx. the same as for the instrumental record. Climate sensitivity is a measure of the magnitude of the system response to a particular forcing, such as $\mathrm{CO}_{2}$ changes; it is essentially the Holy Grail of greenhouse gas climate studies. However, the largest uncertainty in the sensitivity estimate of Hegerl et al. (2006) was due to the magnitude of vol- canic eruptions. If this uncertainty can be significantly reduced, which now seems to be the case, it will significantly narrow the range of uncertainty in the paleoclimate sensitivity estimate-a prospect we plan to explore after the initial paper has been written.

Full documentation of the scaling and time series is now being prepared for publication. The database for the reconstruction plus the volcano time series of forcing, interpolated to ca. 10 day intervals for the purpose of use in climate model simulations, will be released upon publication.

\section{References}

Hegerl, G., Crowley, T., Baum, S., Kim, K.-Y. and Hyde, W., 2003: Detection of volcanic, solar, and greenhouse signals in paleo-reconstructions of Northern Hemisphere temperature, Geophysical Research Letters, 30(5): 1242, doi:10.1029/2002GL0166335.

Hegerl, G., Crowley T., Hyde, W. and Frame, D., 2006: Constraints on climate sensitivity from temperature reconstructions of the last millennium, Nature, 440: 1029-1032.

Jones, P., Briffa, K., Barnett, T., and Tett, S., 1998: High resolution palaeoclimatic records for the last millennium: Interpretation, integration, and comparison with General Circulation Model control-run temperatures, The Holocene, 8(4): 455-471.

Keen, R., 1983: Volcanic aerosols and lunar eclipses, Science, 222 1011-1013.

Sato, M., Hansen, J., McCormick, M. and Pollack, J., 1993: Stratospheric aerosol optical depths, 1850-1990, Journal of Geophysical Research, 98: 22987-22994.

For full references please consult:

www.pages-igbp.org/products/newsletter/ref2008_2.html 